\title{
Emergency Health Services
}

\section{A. JAMES THOMAS, M.S.P.H., M.S.A.}

$\mathrm{T}$ HE POPULATION explosion in the United States, from 100 million in 1915 to an estimated 300 million in the year 2000 , is of great significance to all divisions of the Public Health Service, but it has special significance for the Division of Health Mobilization. This division, founded in 1959, is responsible for assuring that health services are available to all U.S. citizens in a disaster. It coordinates the emergency services of all divisions of the Service and maintains liaison with other government agencies. It is reasonable to expect that as the population grows and technological changes occur, the number and severity of emergency situations will increase.

\section{Disasters}

An increasing population means more potential victims if a disaster occurs. Few areas of this country could sustain a disaster without considerable loss of life and property, but in the huge urban complexes millions of people could be affected.

The growth of industry and the advancements in technology have greatly increased the possibilities of manmade disasters. The frequency of incidents involving explosions and the accidental release of hazardous substances has shown a marked increase in recent years. The greatest potential threat to public health is accidental nuclear explosion or nuclear warfare.

The distinction generally made between natural and thermonuclear disasters implies that the two emergencies have no common elements. On the contrary, they have many similar phys-

Mr. Thomas is chief of the Planning and Evaluation Branch, Division of Health Mobilization, Public Health Service. ical reactions. The impact of wind at certain distances from ground zero of a thermonuclear attack, for example, would be comparable to that in a hurricane or a tornado. Windborne objects, in either case, would be a major cause of injuries.

In some cases, hurricanes, tornadoes, and earthquakes cause tidal waves, which could also occur after a thermonuclear detonation at or near shorelines. Thus flooding could occur as a result of natural disasters, thermonuclear attack, or simply from excessive rainfall or melting snowpacks. The physical effects of fires and explosions on individuals are obviously comparable to the effects of thermonuclear explosions.

Areas may become inaccessible in either type of disaster. It is equally unsafe to enter an area where fires are extensive, where large gas tanks are likely to explode, or where high levels of radioactive fallout exist.

While natural disasters usually affect only a few metropolitan areas, a national disaster could affect almost every locality in the country.

At present, there are 225 Standard Metropolitan Statistical Areas in the United States. Many or most of the industrial-population-transportation complexes or military targets could be attacked simultaneously. If this happened, a third or more of the nation's citizens could become casualties, half of the hospital beds could be lost, two-thirds or more of the nation's health and medical supplies could be destroyed, and the breakdown of environmental health safeguards could result in an enormous increase in the incidence of communicable disease.

In natural disasters, destruction is limited to a relatively small area. Communities can rely on the many State, regional, Federal, and other agencies that stand ready to help when needed. 
In a nuclear or national disaster, destruction could affect all areas. The community might have to rely entirely on its own resources for survival and recovery.

\section{Local Disasters}

The extent of local disaster planning varies throughout the nation. The frequency and types of disasters, the degree of civil defense planning and the development of emergency organizational structures, the absence or presence of emergency operating centers, and previous experiences with health problems associated with disasters are some of the factors that influence the extent of cooperative planning and operations.

Because of the transient nature of natural disasters and the support available from external sources, local officials often have not felt compelled to organize their governments to cope with such emergencies. They know that in case of a natural disaster they can get help from outside sources. Many feel that in a national disaster the situation would be totally hopeless and no amount of preparation or planning would be helpful. Apparently, they have not considered the facts.

If the number of casualties reached the most dire prediction, there would still be a greater number of Americans living after a nuclear attack than were living in this country in the early 1900's. Approximately 100 million citizens would need care, and the responsibility would rest with the communities. A good local plan of action and preparedness would be the prime factor for response to and recovery from such a disaster.

A severe natural disaster that flooded highways and severed telephone lines would also force a community to be self-reliant. The value of a local plan is not limited to national disasters; it is the only effective way for a community to cope with any type of health emergency.

Action is equally as important as planning. A community that has drawn up a plan but never practiced it is comparable to a school that has a plan for fire evacuation but has never held a fire drill. Both offer only partial protection. In emergencies, people are willing and eager to help, but willingness and eagerness are not substitutes for training and practice.
Each community must develop an organized capability for fitting into the State and Federal patterns of management of health resources. The success of all plans depends upon the ability of the local, State, regional, and Federal agencies to work together, particularly in the event of a thermonuclear attack.

There are many ways to develop local and State disaster plans, but all plans must include the following steps:

- The strengthening of existing health and medical programs that can contribute to the alleviation of emergency health situations.

- The creation of a standby emergency health organization.

- Selection of key staff and alternates to carry out the emergency functions.

- Training of personnel in their emergency duties.

- Development of a communications capability to facilitate interagency and interjurisdictional cooperation and to obtain supporting resources necessary to the provision of emergency health services.

- Development and positioning of records essential to the conduct of effective emergency operations.

- Obtaining supplies and other resources for emergency use-Packaged Disaster Hospitals are an example.

- Identification of the location of other health supplies and equipment.

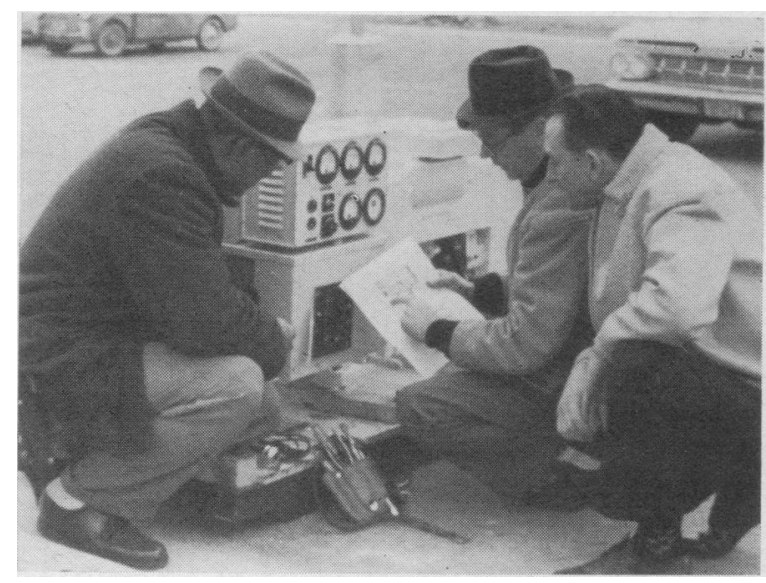

A generator is one of the basic pieces of disaster equipment in every Packaged Disaster Hospital 


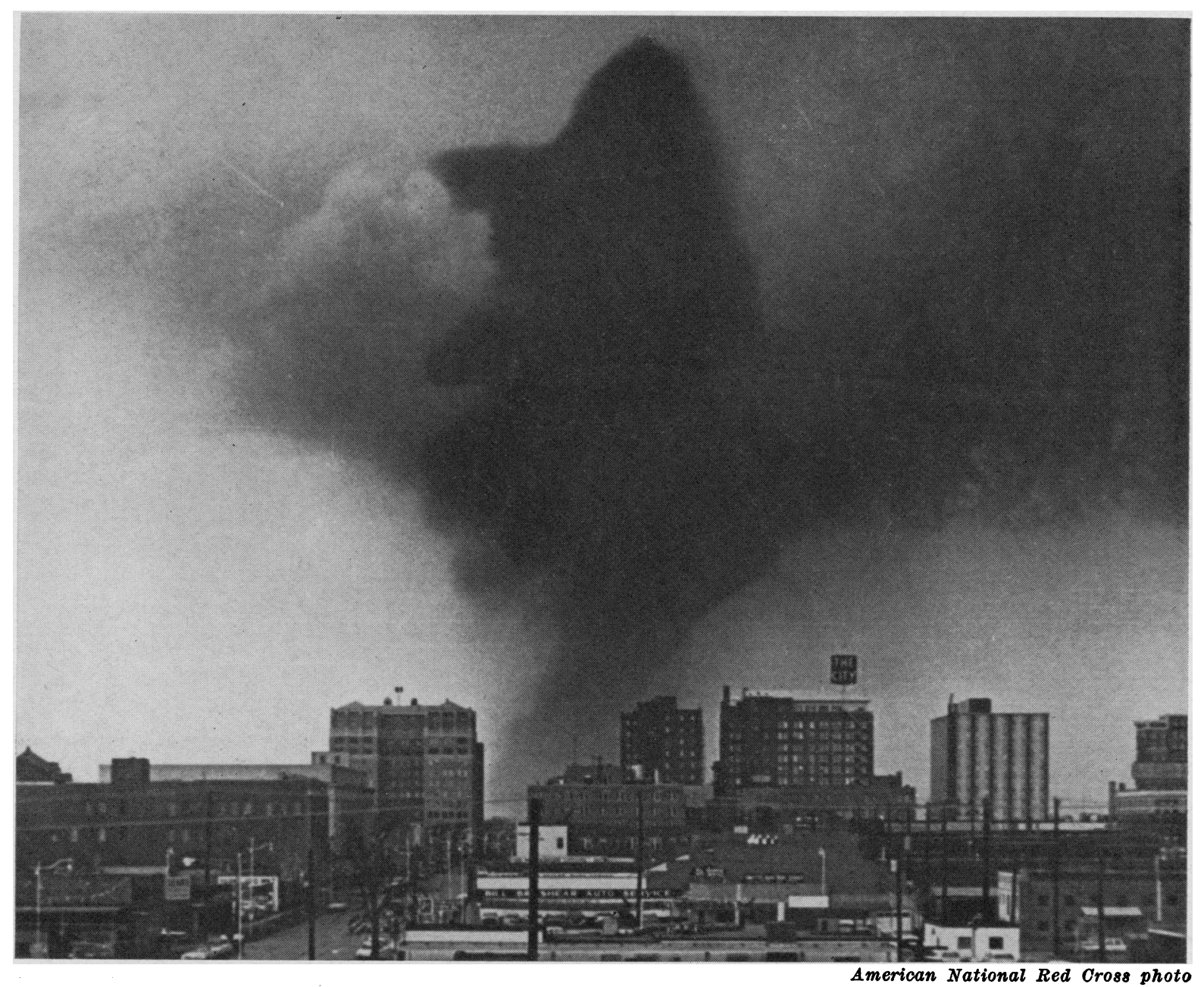

Tornado approaching Wichita Falls, Tex., April 1964

- Conduct of tests and exercises to improve standards for disaster operations.

- Encouraging the development of emergency plans for hospitals.

\section{National Disasters}

The scope and magnitude of a national disaster demands the reorganization of the local emergency health structure to $(a)$ focus its efforts on imperative program needs, $(b)$ use available health and medical resources to the best advantage, and $(c)$ provide a mechanism for resupply of essential equipment and materials. The need for such reorganization is the realization that no outside help would be available for an indeterminate length of time-perhaps 2 weeks or more.

A national disaster demands the suspension of nonessential programs. Personnel not engaged in priority activities should be assigned to tasks which they are qualified to perform or could perform with prior training. All specialized health and medical personnel should be engaged in saving lives under austere conditions. A plastic surgeon, for example, would find himself in general practice-elective or cosmetic surgery would have to be delayed. Laboratory personnel-professional, private, or industrialwith appropriate indoctrination and adaptation of equipment, could support emergency health and medical activities through generalized laboratory services such as clinical, food, and drug, and environmental health analyses.

In a national emergency, the area emergency health organization would be responsible for managing and using efficiently the available re- 
sources. The best possible management, however, might not enable authorities to fill the extraordinary demands. Soon they would have to seek additional supplies, equipment, and supporting services from other areas.

The determination of how to obtain and provide such resources to the areas needing them the most is one of the major justifications for the development of State and Federal emergency organizational structures. Each level must be prepared, within the context of national policies and guidance, to evaluate local program needs and to assist in filling the needs.

The State emergency organizational structure emphasizes the major program and resource support areas at the State level. The organizational configuration at the regional and headquarters levels is basically the same as that for the State. Local organization emphasizes the provisions of direct emergency health services.

The resupply system would operate, in general, in the following manner:

1. Professional personnel in the communities would report to the State on the local health and medical program priorities, the quantities of resources on hand and the time when the supply is expected to become exhausted, and the time-phased operational health supply needs.

2. Professional program personnel at the State level would evaluate the needs of the various communities or areas throughout the State and direct that the remaining resources within the State be made available to the communities or areas most capable of using them for health and medical purposes. In some cases, it would be necessary to work with the State resources priority boards to decide on these matters. The mechanics of resupply would be referred to the resource managers. When needs exceeded resources, the resource managers would refer their requests to the regional emergency health service.

3. The professional personnel of the regional emergency health service would evaluate the requests of the States and direct the regional resource managers concerning any intraregional movement of remaining resources and the referral to headquarters of requests for additional resources.

4. The professional personnel of the Federal Emergency Health Service would evaluate pro- gram needs among the regions and direct its resource managers to submit claims for health supplies and equipment to the Office of Defense Resources (ODR). The ODR would then adjudicate the claim and authorize $(a)$ the Federal Emergency Health Service to allocate available stocks in warehouses to the emergency health service regions, or (b) authorize the Business and Defense Services Administration (BDSA) to release producers' inventories or initiate new production for subsequent allocation by the Public Health Service to the regions. The Federal Emergency Health Service would then instruct the BDSA concerning points of delivery of those quantities of items manufactured and allocated for domestic health.

Emergency health organizations at each level fit into the basic governmental structure. This arrangement permits health personnel to be placed in the vertical Office of Emergency Planning-Office of Civil Defense policy-information channel, to communicate with their

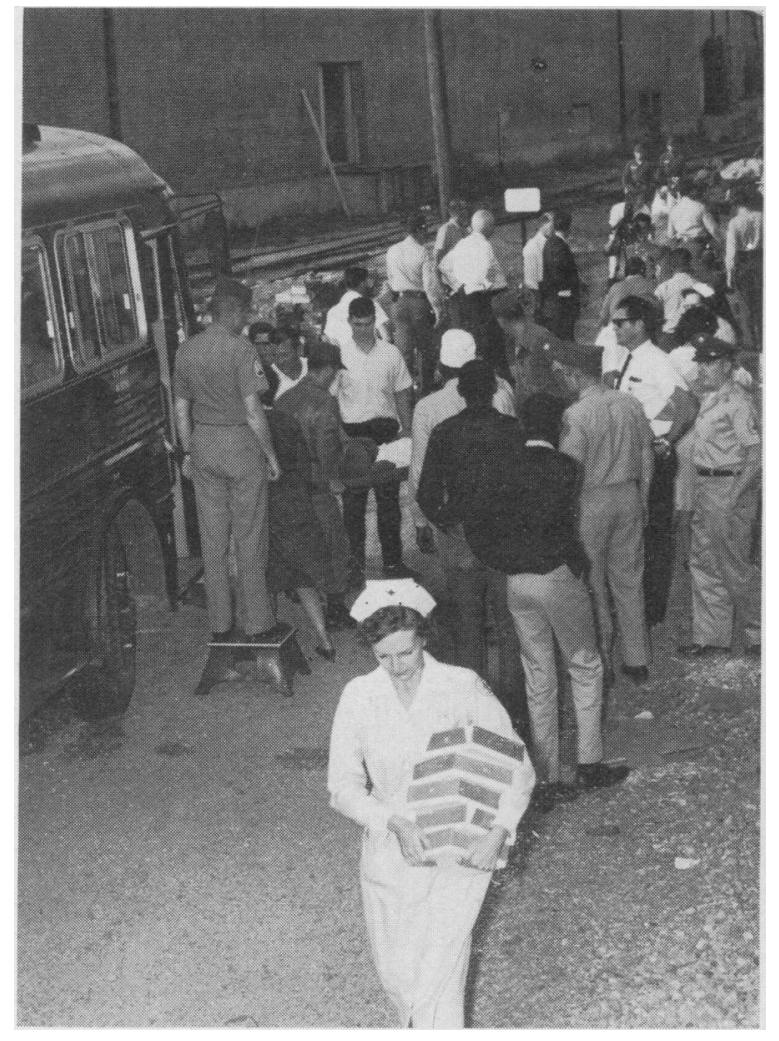

Chlorine barge, sunk by Hurricane Betsy, forced evacuation of Louisiana residents in 1965 


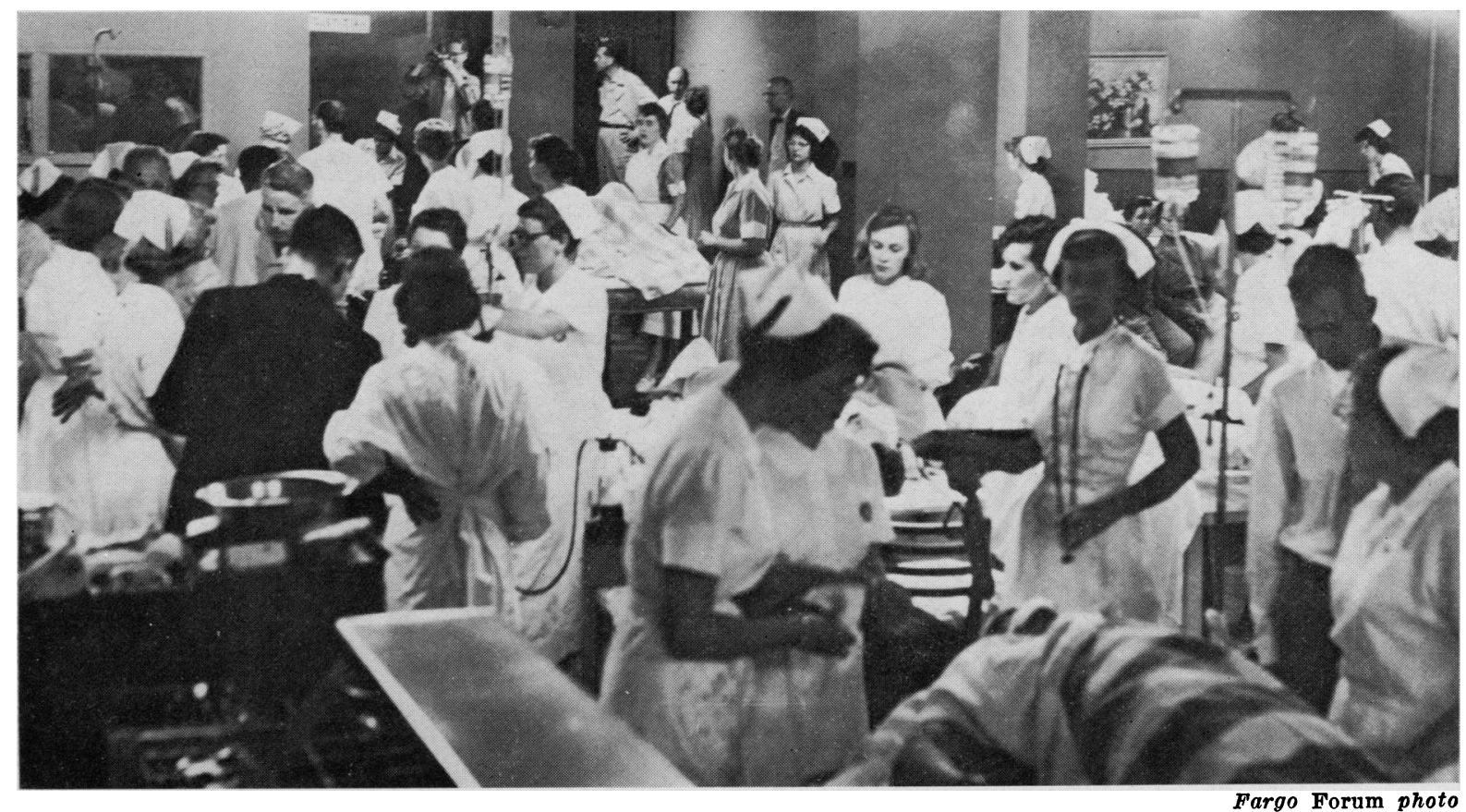

Cafeteria at St. Luke's Hospital, Fargo, N. Dak., was converted into a first aid room to provide care for 70 victims of a tornado in 1957

counterparts at each level concerning Federal policy, and to relay upward information of use in program policy decision making.

Advance preparation is necessary at all levels if the system is to work. The Federal Emergency Health Service has developed a comprehensive plan and organization. It has selected cadremen for both policy and operational sites. Records have been prepared and prepositioned at each site for guidance in appropriate postattack actions. Many steps have been taken to keep cadremen abreast of their responsibilities. Tests and exercises are held to improve operational capabilities. The regional Public Health Service offices have also developed plans similar to those at headquarters.

The Division of Health Mobilization has issued a Model State Emergency Health Services Plan to the States. More than half of the States have developed plans of this kind and others are being developed. Local prototype plans have also been developed for guidance. A prototype Standard Metropolitan Statistical Area Plan is available from the division. Plans, organizational structures, and procedures at all levels are interrelated and comparable within practical limits.

\section{Summary}

The growth of the population and of technology will result in increasingly severe emergency health situations. Although the numbers of natural disasters may not increase, the tornadoes, floods, hurricanes, and earthquakes that do occur will have a greater potential of victims. Manmade disasters-accidental release of hazardous substances or nuclear accidents or even nuclear warfare-could increase as the production and use of chemicals and nuclear materials increase. The only way to prepare for these anticipated disasters is through planning and practice.

The Federal and State governments have comprehensive plans of organization and action, but the majority of the local governments have not prepared or practiced their plans. The greatest present need in emergency health services is at the local level. Local officials must assume the responsibility for organizing and activating their governments and agencies. Using guidance materials available from State and Federal agencies, they must develop plans, organizational structures, and procedures that will fit into the State and Federal patterns for management of health resources. 


\section{Medical Laboratory Manpower Recommendations}

Recommendations stemming from the national conference on manpower for the medical laboratory, held last fall under the auspices of the National Committee for Careers in Medical Technology, cover recruitment, education, training, utilization, and career advancement of laboratory personnel. The recommendations deal with changes presently occurring and anticipated for the future in laboratory procedures, automation, functions, structure, and demands for laboratory services.

Highlights of the recommendations follow.

Need for information. More information is needed on present staffs of medical laboratories as a basis from which to project changes and needs. This led to recommendations for $(a)$ a survey to obtain detailed job descriptions of present laboratory positions and definitions of skills required for each, $(b)$ reassessment of laboratory career categories, based on the inventory of job descriptions, and $(c)$ development and adoption of a uniform national system for reporting laboratory workloads.

Effects of automation. In view of technological changes in laboratory medicine brought about by automation and computers, a study should be made of the new specialties and disciplines that will be needed and of the curriculums and training required for them. Potential new courses suggested for laboratory personnel were biomedical equipment operation, biomedical engineering, computer programing, and isotope technology. These courses could be offered in junior or 4-year colleges, or both.

Attracting and recruiting manpower. Allied health careers should be promoted with information directed to science teachers, guidance counselors, librarians, parents, and students, starting with the upper elementary grades. Also recommended was expansion of recruitment to reach new sources of manpower, such as scientists trained in chemistry and physics, inactive medical technologists, handicapped persons whose disabilities do not preclude laboratory work, married women with science backgrounds, older age groups, persons with outmoded technical skills, economically and educationally underprivileged persons with ability, and Armed Forces veterans.

Education. It was recommended that laboratory professionals direct efforts and influence to help upgrade the quality of science education in elementary and high schools, particularly rural and overcrowded urban schools. Also, assistance and guidance should be provided junior colleges and vocational schools for developing educational programs for medical laboratory careers.

Since medical technology degrees do not have baccalaureate standing in all universities, it was recommended that medical technology education be strengthened, particularly in the clinical fourth year. Further, development of core science courses for all college students preparing for health careers would permit joint use of faculty and laboratory facilities and promote mobility between health careers.

Strengthening and expanding continuing and graduate education for medical laboratory personnel were considered important factors for improving laboratory performance and keeping abreast of technological advances. Exploration and development of new curriculums and teaching methods using selfinstruction more effectively was also recommended.

Enriching careers. To insure greater mobility and opportunity for advancement in laboratory careers, equivalency tests should be developed to grant credit for skills acquired outside of formal education and to encourage capable persons to seek advancement. Career opportunities should be improved and salaries increased, particularly in supervisory positions in which expert administrators and other specialists are needed.

Licensure, certification, and accreditation. Scientific disciplines engaged in laboratory medicine should be consulted and represented, along with the public, in licensing programs. State licensure laws should be based on standards established by national medical and scientific organizations. Accrediting and certifying agencies should explore the possibility of offering their services to all schools requesting evaluation and to graduates of nonaccredited as well as accredited programs. 